\title{
RECONSTITUIÇÃO PALEOAMBIENTAL DE DEPÓSITOS ALBIANOS NA BORDA LESTE DA BACIA DE GRAJAÚ, MA
}

\author{
MARIA CAROLINA DA CRUZ MIRANDA ${ }^{1} \&$ DILCE DE FÁTIMA ROSSETTI²
}

\begin{abstract}
Resumo Depósitos albianos expostos nas margens do Rio Itapecuru, borda leste da Bacia de Grajaú, apresentam quatro associações faciológicas típicas de ambientes deltaicos. Depósitos de frente deltaica consistem em arenitos com geometria lobada, sendo internamente maciços, deformados ou contendo estratificações cruzadas, e organizados em padrão de espessamento e granocrescência ascendentes. Depósitos de frente deltaica retrabalhada por onda consistem em camadas tabulares de arenito contendo estratificações cruzadas swaley, laminação ondulante, estratificação cruzada tabular de baixo ângulo, além de estruturas de corte e preenchimento (scour-and-fill) de grande escala. Depósitos de barras distais são caracterizados por arenitos similares aos depósitos de frente deltaica retrabalhada por onda, porém ocorrendo sob forma de corpos isolados, relativamente mais delgados e distribuídos em meio a argilitos laminados ou maciços. Depósitos representativos de ambientes deposicionais de baixa energia, que possivelmente registram prodelta, plataforma restrita e planície de lama, incluem argilitos laminados e maciços, além de calcários, com feições de exposição subaérea, incluindo-se marcas de raízes, gretas de contração, dissolução por ação de água meteórica, bem como pegadas de dinossauros. A arquitetura das associações de fácies revelou a presença de três unidades estratigráficas definidas por superfícies de descontinuidade, marcadas por cimentação carbonática, concentrações de fósseis retrabalhados, e depósitos residuais consistindo em arenitos grossos e conglomerados. A distribuição espacial dessas unidades, bem como de suas associações faciológicas, mostram que os depósitos finos representativos de ambientes de prodelta, plataforma restrita e planície de lama, tornam-se progressivamente mais abundantes de sudeste para noroeste da área de estudo, bem como em direção ao topo das sucessões, mostrando progressivo afogamento do sistema deltaico. Inundações pontuadas, registradas por superficies de descontinuidade, resultaram em padrão estratal dominantemente retrogradacional, o que sugere que o sistema deltaico em questão pode ter sido gradativamente abandonado em função de fase transgressiva.
\end{abstract}

Palavras-chave: paleoambientes, Albiano, análise faciológica, sistema deltaico, tempestades, Bacia de Grajaú

\begin{abstract}
PALEOENVIRONMENTAL RECONSTRUCTION OF ALBIAN DEPOSITS IN THE EASTERN GRAJAÚ BASIN, MA The Albian deposits of the Itapecuru Group exposed at the margins of the Itapecuru River, near the town of Coroatá, eastern Grajaú Basin, were investigated concerning their sedimentological, stratigraphic and palaeontological aspects. The study showed that these strata include sandstones, shales and limestones formed in depositional environments usually found in deltaic systems. They include: 1. delta front, consisting of sandstone lobes, either amalgamated or separated by thin shale layers, and which are internally characterized by massive, deformed or cross-stratified sandstones arranged into thickening- and coarsening upward successions; 2. wave-dominated delta front, consisting of sandstones in a variety of wavy laminations, including swaley cross-stratification, undulating parallel-lamination, low- angle cross- stratification and large- scale scour-and-fill structures; 3. distal bar, characterized by sandstones with sedimentary structures similar to delta front deposits, but forming thinner lenses isolated within shales; and 4. prodelta/restricted shelf/ mud flat, which includes the finest-grained lithologies of the study area, consisting of laminated to massive shales and limestones. Features attributed to subaereal exposure, such as root marks, mudcracks, karstic holes formed by dissolution under influence of meteoric water, and dinosaur footprints, are all locally found in association with these deposits. The analysis of facies architecture revealed three stratigraphic units, defined by discontinuity surfaces marked by one or more of the following elements: calcitic cement, concentrations of fossil fragments, and a lag of coarse-grained sandstone and conglomerate. Despite the internal organization into prograding cycles, typical of deltaic systems, the distribution of the stratigraphic units and facies associations shows that muddier deposits, attributed to low-energy environments ranging from prodelta to restricted shelf and mud flat, become more abundant from southeast to northwest in the study area, as well as towards the top of the sections, recording progressive drowning of the deltaic system. Punctuated floodings took place, being represented by discontinuity surfaces, characterizing a retrogradational stratal pattern, suggesting abandonment of the deltaic system due to an overall transgression.
\end{abstract}

Keywords: paleoenvironment, Albian, facies analysis, deltaic system, storms, Grajaú Basin

INTRODUÇÃO A grande maioria do preenchimento sedimentar do rift intracontinental correspondente à Bacia de São Luís-Grajaú inclui depósitos cretáceos formados a partir do Neoaptiano. Em afloramentos, depósitos representativos do estágio pré-rift desta bacia são bem documentados nas regiões de Codó e Grajaú, nas bordas leste e sul da bacia, respectivamente, onde são representados pela sucessão sedimentar designada de Codó-Grajaú (Paz 2000; Paz \& Rossetti 2001; Rossetti et al. 2004). Depósitos albianos e albo-cenomanianos, representativos dos estágios rift/drift, têm sido documentados em várias outras áreas localizadas na borda norte (Rossetti 1997; 1998), sudeste (Anaisse Jr. 1999) e sul (Rossetti \& Góes 2003) da bacia, onde são incluídos no Grupo Itapecuru (Rossetti \& Truckenbrodt, 1997). Neste grupo, as unidades mais detalhadamente estudadas correspondem às formações Alcântara, de idade albo-cenomaniana, e Cujupe, de idade incerta entre o Neocretáceo e o Eoterciário. Por outro lado, depósitos albianos inferiores/médios, que fazem parte da Unidade Indiferenciada (Rossetti \& Truckenbrodt 1997), foram originalmente descritos somente com base em dados de sub-superfície.

Estudos palinológicos preliminares confirmaram a ocorrência de depósitos eo-mesoalbianos em exposições naturais ao longo do Rio Itapecuru, borda leste da Bacia do Grajaú (Rossetti et al. 2001a, b; Arai 2001). Apesar desta constatação, estes depósitos são, ainda, inadequadamente descritos, dificultando reconstituições paleoambientais, bem como sua distinção com outros depósitos cretáceos ali expostos. A constatação da ocorrência desta unidade eo-mesoalbiana em superfície fornece, pela 
primeira vez, uma oportunidade ímpar para a reconstituição dos sistemas deposicionais representativos da fase rift da Bacia de São Luís-Grajaú.

Este trabalho tem por objetivo descrever as características faciológicas e a estratigrafia de rochas cretáceas expostas ao longo do Rio Itapecuru, entre as localidades de Timbiras e Pirapemas (Fig. 1A), onde a idade eo-mesoalbiana foi determinada com base na ocorrência da palinozona Complicatisaccus cearensis (P-280). A excelente preservação de estruturas sedimentares, associadas à ocorrência de rochas calcárias, permitiu um estudo detalhado que culminou com a reconstituição dos ambientes de sedimentação. Apesar da natureza descontínua das seções estudadas, a ocorrência de afloramentos lateralmente contínuos por algumas centenas de metros possibilitou a análise da arquitetura das associações de fácies, que foram importantes na proposição de um modelo deposicional e no entendimento de sua evolução através do tempo.

CONTEXTO GEOLÓGICO A Bacia de Grajaú, que abrange uma área de aproximadamente $130.000 \mathrm{~km}^{2}$ no Estado do Maranhão, está inserida em um rift intracontinental (Azevedo 1991; Góes \& Rossetti 2001) formado ao longo da margem equatorial brasileira durante o processo de separação dos continentes sul-americano e africano. Seu preenchimento é similar ao da Bacia de São Luís, com a qual está conectada a norte, consistindo principalmente em rochas cretáceas. Estas estão representadas, da base para o topo, pela sucessão litoestratigráfica Codó-Grajaú, de idade aptiana, sobreposta por depósitos inseridos no Grupo Itapecuru (Rossetti \& Truckenbrodt 1997). Este grupo consiste na Unidade Indiferenciada (Eo-Mesoalbiano), Formação Alcântara (Neoalbiano-Cenomaniano), e Formação Cujupe (Neocretáceo-? Eoterciário) (Fig. 1B).

A análise em sub-superfície levou ao reconhecimento de
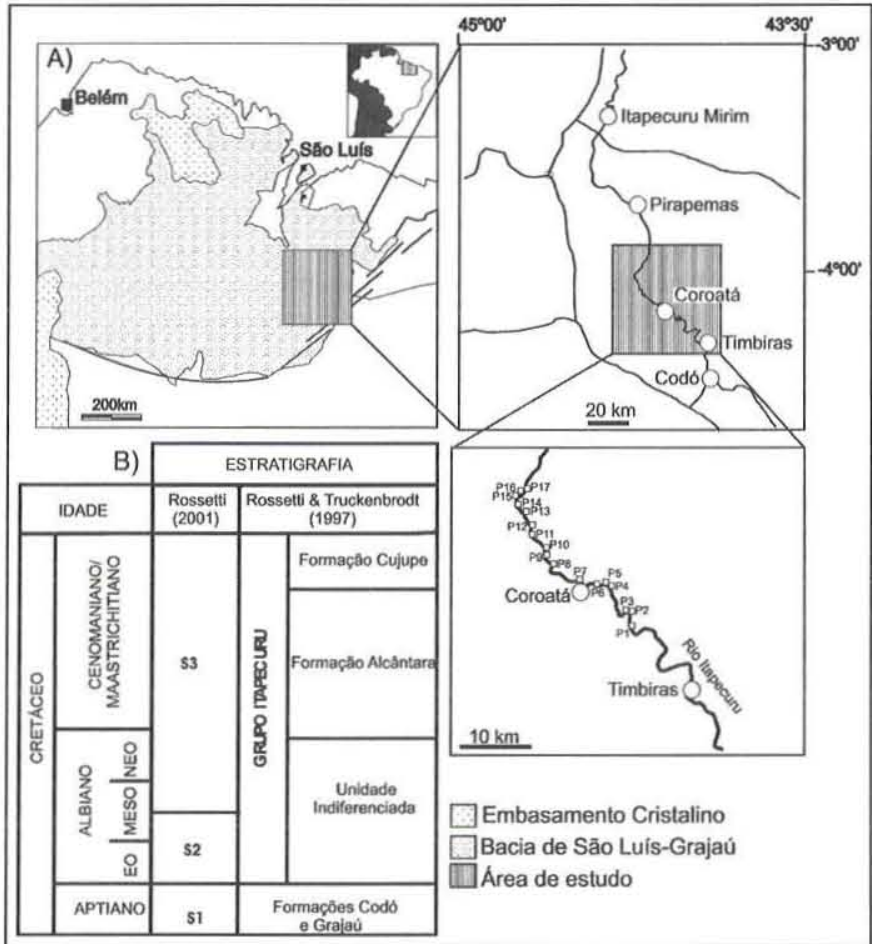

Figura 1: A) Mapa de localização da área de estudo na porção leste da Bacia de Grajaú, Estado do Maranhão (modificado de Rossetti et al., 2001), com indicação dos afloramentos de depósitos albianos/cenomanianos estudados. B) Coluna estratigráfica da Bacia de São Luis-Grajaú. três seqüências deposicionais de segunda ordem, limitadas por discordâncias regionais: seqüência deposicional S1, que inclui as formações Codó e Grajaú (Neoaptiano/Albiano); seqüência deposicional S2, correspondente à parte inferior/média da Unidade indiferenciada (Eo-Mesoalbiano); seqüência deposicional S3 (Mesoalbiano/Neocretáceo), que inclui a porção superior da Unidade Indiferenciada, bem como as formações Alcântara (Neoalbiano/Cenomaniano) e Cujupe (Neocretáceo?) (Rossetti \& Truckenbrodt 1997) (Fig. 1B). As duas primeiras seqüências, que incluem estratos aluviais a marinho-transicionais, estão subdivididas em três unidades organizadas em tratos de sistema de mar baixo, mar transgressivo e mar alto. A terceira seqüência foi formada durante o trato de sistemas transgressivo a mar alto, sendo representada por ciclos de preenchimento de vales incisos (Rossetti 2001).

DESCRIÇÃO FACIOLÓGICA Os depósitos eo-mesoalbianos estudados incluem arenitos em geral micáceos e estratificados, argilitos e calcários. Arenitos e argilitos têm coloração variando de creme-amarelado, cinza, vermelho-chocolate a esverdeado, enquanto calcários são de coloração branca a cinza. Estes estratos podem ser lateralmente contínuos ou, mais comumente, lenticulares, sendo descritos sob forma de 12 fácies (Tabela 1). Estas foram agrupadas em quatro associações atribuídas a ambientes de frente deltaica (associação de fácies A), frente deltaica com retrabalhamento de onda (associação de fácies B) e barra distal (associação de fácies C). Além disto, dada a dificuldade de critérios diagnósticos, depósitos representativos de ambientes de baixa energia, que podem incluir desde prodelta, plataforma restrita e planícies de lama, foram englobados em uma mesma associação de fácies (associação de fácies D) (Tabela 2).

Associação A Esta associação, com $7 \mathrm{~m}$ de espessura média, consiste em lobos arenosos variando entre $0.5-2 \mathrm{~m}$ de espessura e $50-100 \mathrm{~m}$ de comprimento, com geometria freqüentemente sigmoidal (Fig. 2A). Os lobos ocorrem amalgamados ou individualizados por finas camadas (poucos centímetros) de argilitos laminados (fácies Agl). Internamente, ocorrem arenitos maciços (fácies Am), com estruturas de deformação sin-sedimentar (fácies Ad), ou estratificação/laminação cruzada tabular e acanalada (fácies At/a e Alc, respectivamente) (Fig. 2B e 2C). Os estratos cruzados, que exibem freqüentemente superfícies de reativação e/ou recobrimentos argilosos, acham-se orientados dominantemente na direção ENE e ESE, o que é coincidente com a direção de inclinação dos lobos (Fig. 2D). Onde depósitos argilosos mais espessos acham-se presentes, eles formam acamamentos heterolíticos dos tipos wavy, flaser, streaky e lenticular (fácies $\mathrm{P} / \mathrm{Ah}$ ), que gradam para cima a arenitos, resultando em sucessões granocrescentes ascendentes. A base dos lobos pode ser ainda abrupta, sendo salientada por abundantes intraclastos sub-angulosos de argila. Localmente estes podem, também, se acumular em depressões rasas $(<0.3 \mathrm{~m}$ de profundidade), formando conglomerados intraformacionais (fácies $\mathrm{Ci}$ ).

Argilitos negros, ricos em matéria orgânica vegetal (fácies Agm) foram também incluídos na associação de fácies A. Estes depósitos formam camadas lenticulares de até $0,2 \mathrm{~m}$ de espessura, ou ocorrem como preenchimento de depressões rasas de igual espessura. Localmente estes depósitos formam turfas, onde ocorrem fragmentos de âmbar de até $10 \mathrm{~cm}$ de diâmetro, além de nódulos de pirita de até $1 \mathrm{~cm}$ de diâmetro.

Associação B Esta associação inclui arenitos finos a muito finos, bem selecionados, os quais ocorrem sob forma tabular a lenticular, tipicamente ondulante, que são interdigitados aos depósitos de frente deltaica. Estes estratos possuem espessuras variando entre $0,4-1,5 \mathrm{~m}$ e inclui dominantemente arenito com 
estratificação/laminação plano-paralela/ cruzada ondulante, por vezes cavalgante (fácies Alo; Fig. 3A, B) e arenito com estratificação swaley (fácies As) (Fig. 3C), ocorrendo secundariamente arenito com estratificação/laminação plano-paralela horizontal (fácies App), arenito com laminação cruzada (fácies Alc), arenito deformado (fácies Ad), pelito/arenito com acamamento heterolítico (fácies $\mathrm{P} / \mathrm{Ah}$ ), argilitos maciço (fácies Agm) e laminado (fácies $\mathrm{Agl}$ ), além de conglomerados fossilíferos (fácies Cf; Fig. 3D) e intraformacional (fácies Ci). Os últimos são, em geral, maciços, ou mostram estratificação cruzada incipiente (Fig. 3E), ocorrendo como camadas delgadas residuais de poucos centímetros de espessura e lateralmente descontínuas, sobre as superfícies ondulatórias ou depressões côncavas de até $0,5 \mathrm{~m}$ de profundidade.

Associação C Esta associação, com aproximadamente $6 \mathrm{~m}$ de espessura, constitui-se principalmente em arenitos com coloração branco-amarelada a esverdeada (Fig. 4A), que ocorrem interdigitados com litologias argilosas cinza-esverdeadas a marrom-avermelhadas. Os arenitos, com espessuras médias de 0,20,3 m e comprimentos de 20-30 m, são lenticulares, sendo que lentes sucessivas podem formar um conjunto com adelgaçamento para cima. A base dos arenitos pode ser brusca ou gradacional, neste último caso formando sucessões granocrescentes ascendentes, enquanto o topo é tipicamente brusco. Internamente, as lentes caracterizam-se por estratificação/laminação cruzada tabular/acanalada (fácies At/a e Alc), podendo ser ainda deformadas (fácies Ad) ou maciças (fácies Am). Medidas de estratificações cruzadas indicam fluxos orientados predominantemente para NNE (Fig. 4C). As litologias argilosas que se intercalam às lentes arenosas formam, dominantemente, acamamentos heterolíticos dos tipos wavy e lenticular (fácies P/Ah; Fig. 4B). Argilitos laminados (fácies $\mathrm{Agl}$ ) podem ocorrer na base destes estratos, configurando ciclos com granocrescência ascendente.

Associação D Nesta associação, incluem-se todas as litologias argilosas que ocorrem associadas a camadas de calcário com siliciclásticos, formando sucessão lateralmente contínua (Fig. 5A). Os argilitos são laminados (fácies Agl), de coloração cinza escuro a claro e verde-oliva, ou maciços (fácies Agm), com aspecto localmente endurecido, calcífero, e de coloração vermelho-chocolate a violácea (Fig. $5 \mathrm{~B}$ e $5 \mathrm{C}$ ); nestes últimos são comuns marcas de raízes. Localmente ocorrem lentes (até $0,35 \mathrm{~m}$ de espessura) de folhelhos negros e esverdeados que se destacam por fauna de invertebrados marinhos. Estes, a serem descritos em um estudo à parte, consistem em um grande número de indivíduos, porém representativos de apenas dois grupos de moluscos: bivalves (paranomídeos, cardiídeos, glicymeridídeos) e gastrópodes (naticídeos, turritelídeos, e ceritídeos). Nos folhelhos negros observa-se, ainda, uma abundância de restos vegetais.

Os calcários (fácies Cs) são caracterizados por corpos tabulares ou lenticulares de até $0,5 \mathrm{~m}$ de espessura, que localmente podem mostrar feições cársticas e gretas de contração (Fig. 5D). Alguns horizontes destacam-se por conter sucessão de feições circulares com cerca de $0,6 \mathrm{~m}$ de diâmetro, atribuídas a pegadas de dinossauros (Fig. 5E). A caracterização petrográfica desta fácies revelou a presença de quatro microfácies, em ordem decrescente de abundância: wackestone/packstone peloidal ou fossilifero, mudstone, packstone com siliciclásticos e grainstone ostracodal (Tab. 3).

MODELO DEPOSICIONAL As diferentes associações faciológicas descritas acima são consistentes com a proposição de um modelo deposicional representado por um complexo de lobos de suspensão, sujeito a retrabalhamento por ondas nor- mais e de tempestade (Fig. 6). A caracterização de um complexo progradacional foi feita principalmente com base na abundância de depósitos formados por lobos de suspensão nas associações de fácies A e B, atribuídas a ambientes de frente deltaica e frente deltaica com influência de onda, respectivamente. A geometria sigmoidal dos lobos, a organização em granocrescência ascendente, a freqüência de depósitos maciços ou com estruturas deformacionais, são concordantes com processos de progradação rápida em ambiente com talude, sujeito a instabilidade gravitacional (Mills 1983; Elliot 1986, Coleman 1988; Orton \& Reading 1993; Glover \& O’Beirne 1994), como é típico em frentes deltaicas.

Feições observadas na associação B, como estratificação/ laminação plano-paralela/cruzada ondulante (fácies Alo), estratificação swaley (fácies As), e superfícies erosivas com escavações seqüenciais simétricas e assimétricas de grande porte, são condizentes com a influência de fluxos combinados (i.e., com componente oscilatória e unidirecional). Estes registram a ação de ondas de grande porte desenvolvidas durante períodos de tempestade (Leckie \& Walker 1982; Swift et al. 1983; Arnott \& Southard 1990; Duke et al. 1991; Cheel \& Leckie 1993; Rossetti et al. 2000; Hill et al. 2003). Feições similares foram registradas em depósitos cretáceos em outras partes da Bacia de São LuísGrajaú (Anaisse Jr. 1999; Anaisse et al. 2001; Rossetti 1997; Rossetti et al. 2000, Rossetti et al. 2001a). Em adição, superfícies de reativação e recobrimentos argilosos da fácies At/a registram freqüentes instabilidades no fluxo, o que pode ser devido à influência, ainda que distal, de fluxo combinado ou de correntes de maré (Allen 1980; Allen 1982; Dalrymple 1992; Tamura \& Masuda 2003). Estes processos podem produzir feições bastante similares no registro geológico (e.g. Johnson \& Baldwin, 1986; Harris \& Eriksson 1990; Amos et al. 1996; Colquholn 1995), e seu reconhecimento na área de estudo atesta redistribuição de pelo menos parte do sedimento depositado na frente deltaica.

Considerando-se o sistema deposicional proposto, a associação de fácies $\mathrm{C}$ é atribuída a ambientes de barras distais. $\mathrm{O}$ padrão granocrescente ascendente sugere aumento da energia do fluxo durante a deposição das lentes individuais. O adelgaçamento de lentes de arenito para cima nas secções registra momentos de abandono da progradação na frente deltaica e, conseqüentemente, retorno às condições de sedimentação por suspensão.

A associação D é atribuída a ambiente deposicional de baixa energia, como revelado pelo domínio de litologia formadas a partir de suspensões. Além disto, a intercalação de argilitos com fácies carbonáticas finas, representadas por wackestone/packstone peloidal ou fossilífero e mudstone, suporta deposição em ambientes calmos. A abundância de pelóides verificada nestas microfácies também sugere ambientes restritos, visto que, tais partículas são comumente relatadas em ambientes lagunares (e.g., Tucker 1994; Adams \& McKenzie 1998). Por outro lado, a ocorrência de packstone com siliciclásticos e grainstone, revela momentos de deposição sob condições de fluxo energia relativamente maior. A presença freqüente de grãos siliciclásticos nas microfácies carbonáticas mostra proximidade com fonte arenosa, o que é consistente com sua intercalação com fácies de arenitos e pelitos, em parte formados por lobos de suspensão registrados por ciclos de arrasamento ascendentes.

Os invertebrados marinhos, exclusivos da associação D, indicam que a bacia de captação do sistema de lobos deltaicos tinha conexão com o sistema marinho. Entretanto, a abundância de espécimens e a baixa diversidade de espécies são consideradas reflexivas de grande estresse ambiental, o que provavelmente se deu pela mistura de água do ambiente marinho com o fluxo fluvial. Considerando-se estas características, bem como a gradação desta associação de fácies para os depósitos de barras 


\begin{tabular}{|c|c|c|}
\hline FÁCIES & DESCRIÇÃO & PROCESSO SEDIMENTAR \\
\hline $\begin{array}{l}\text { Arenito com estratificação } \\
\text { cruzada tabular/acanalada } \\
\text { (At/a) }\end{array}$ & $\begin{array}{l}\text { Arenito fino/muito fino, bem selecionado, coloração } \\
\text { amarelada, micáceo, ocasionalmente feldspático, com } \\
\text { estratificações cruzadas tabulares e acanaladas de médio } \\
\text { a grande porte. Localmente, superficies de reativação, } \\
\text { cobertas por filmes de argila. }\end{array}$ & $\begin{array}{l}\text { Migração de formas de leito com cristas retilíneas e sinuosas, } \\
\text { por fluxo unidirecional em regime inferior. Possivel influência } \\
\text { de correntes de maré e ondas. }\end{array}$ \\
\hline $\begin{array}{l}\text { Arenito com estratificação/ } \\
\text { laminação plano-paralela } \\
\text { horizontal }(\mathrm{App})\end{array}$ & $\begin{array}{l}\text { Arenito fino, bem selecionado, micáceo exibindo } \\
\text { estratificação e/ou laminação plano-paralela horizontal. }\end{array}$ & Deposição por suspensão em regime de fluxo inferior. \\
\hline $\begin{array}{l}\text { Arenito com estratifica-ção } \\
\text { cruzada swaley (As) }\end{array}$ & $\begin{array}{l}\text { Arenito fino a muito fino, contendo estratificação } \\
\text { cruzada swaley de pequeno ou médio porte. Freqüentes } \\
\text { truncamentos de baixo ângulo. }\end{array}$ & $\begin{array}{l}\text { Migração de formas de leito de baixo relevo, associada com } \\
\text { deposição por suspensão, sob condições de fluxo combinado } \\
\text { gerado por ação de ondas de tempestade. }\end{array}$ \\
\hline $\begin{array}{l}\text { Arenito com laminação } \\
\text { cruzada (Alc) }\end{array}$ & $\begin{array}{l}\text { Arenito com laminação cruzada tabular e acanalada com } \\
\text { limites de sets planos. }\end{array}$ & $\begin{array}{l}\text { Migração lateral de micro-ôndulas em regime de fluxo inferior } \\
\text { unidirecional. }\end{array}$ \\
\hline $\begin{array}{l}\text { Arenito com estratificação/ } \\
\text { laminação plano-paralela/ } \\
\text { cruzada ondulante (Alo) }\end{array}$ & $\begin{array}{l}\text { Arenito fino com laminação cruzada tabular cujos limites } \\
\text { dos sets, de até } 20 \mathrm{~cm} \text { de espessura, são ondulados. } \\
\text { Internamente, os foresets são truncados por superfícies de } \\
\text { reativação. Laminações cruzadas ondulantes cavalgantes } \\
\text { são comuns, especialmente próximas à base das camadas } \\
\text { de arenito. }\end{array}$ & $\begin{array}{l}\text { Migração e agradação lateral de formas de leito com relevo } \\
\text { suave sob fluxo combinado e/ou oscilatório. }\end{array}$ \\
\hline Arenito deformado (Ad) & $\begin{array}{l}\text { Arenito fino contendo diversas estruturas de deformação } \\
\text { sindeposicional, tais como dobra convoluta, estruturas em } \\
\text { chama e de sobrecarga, e estratos cruzados com ângulo } \\
\text { dos foresets fortemente inclinados, os quais lateralmente } \\
\text { gradam a arenito maciço. }\end{array}$ & $\begin{array}{l}\text { Deformação do sedimento em estado inconsolidado por } \\
\text { instabilidade gravitacional ou impacto de ondas de tempestade. }\end{array}$ \\
\hline Arenito maciço (Am) & $\begin{array}{l}\text { Arenito fino, bem selecionado contendo acamamento } \\
\text { maciço. }\end{array}$ & $\begin{array}{l}\text { Deposição em condições de alta energia com rápida desaceleração } \\
\text { do fluxo, impedindo a estruturação do sedimento. }\end{array}$ \\
\hline $\begin{array}{l}\text { Pelito/arenito com } \\
\text { acamamento heterolítico } \\
(\mathrm{P} / \mathrm{Ah})\end{array}$ & $\begin{array}{l}\text { Intercalações de arenito fino e argilito, com amplas } \\
\text { variações das proporções de areia e argila, formando } \\
\text { acamamentos heteroliticos dos tipos wavy, flaser, streaky } \\
\text { e lenticular: }\end{array}$ & $\begin{array}{l}\text { Ambiente com alternância freqüente de energia, com deposição } \\
\text { de argila por suspensão durante periodos calmos e areia por } \\
\text { suspensão/ou tração durante energia relativamente mais } \\
\text { elevada. }\end{array}$ \\
\hline Argilito laminado $(\mathrm{Agl})$ & $\begin{array}{l}\text { Argilito cinza esverdeado a verde-oliva, com ocorrências } \\
\text { localizadas de camadas de cor violácea epreta. Laminação } \\
\text { plano-paralela e, ocasionalmente, acamamento lenticular } \\
\text { (lentes de até } 15 \mathrm{~cm} \text { ). Localmente ocorrem argilitos } \\
\text { calcíferos contendo abundantes concentrações de } \\
\text { invertebrados fósseis e restos de vegetais. }\end{array}$ & $\begin{array}{l}\text { Deposição por suspensão em condições de baixa energia, com } \\
\text { periodos de anoxia. }\end{array}$ \\
\hline Argilito maciço (Agm) & $\begin{array}{l}\text { Argilito de coloração marrom-chocolate a marrom- } \\
\text { avermelhada e, ocasionalmente, verde. Calcífero, } \\
\text { endurecido e, localmente, topo com concentrações de } \\
\text { paligorsquita. }\end{array}$ & Alteração da fácies $\mathrm{Agl}$ por processos pedogenéticos. \\
\hline $\begin{array}{l}\text { Calcário com siliciclásticos } \\
\text { (Cs) }\end{array}$ & $\begin{array}{l}\text { Lentes e camadas com espessuras de até } 20 \mathrm{~cm} \text { de calcário. } \\
\text { Topos podem exibir marcas de onda, feições cársticas, } \\
\text { gretas de contração e marcas de raizes. Petrograficamente } \\
\text { variam de mudstone a grainstone. }\end{array}$ & $\begin{array}{l}\text { Acúmulo de material carbonático sob condições de baixa a alta } \\
\text { energia. }\end{array}$ \\
\hline $\begin{array}{l}\text { Conglomerado } \\
\text { intraformacional }(\mathrm{Ci})\end{array}$ & $\begin{array}{l}\text { Conglomerado de matriz síltico/arenosa, com clastos de } \\
\text { argila autosustentados. }\end{array}$ & $\begin{array}{l}\text { Erosão de camadas de argilito, com retrabalhamento formando } \\
\text { clastos em condições de fluxos de altíssima energia. }\end{array}$ \\
\hline $\begin{array}{l}\text { Arenito grosso/ } \\
\text { conglomerado fossilifero } \\
\text { (Cf) }\end{array}$ & $\begin{array}{l}\text { Delgados horizontes lateralmente continuos de arenito } \\
\text { maciço, calcífero, de granulometria dominantemente } \\
\text { grossa e grãos bem arredondados, e que lateralmente } \\
\text { gradam a conglomerados. Localmente, forma horizontes } \\
\text { fossiliferos contínuos constituídos de fragmentos de } \\
\text { conchas de bivalves, gastrópodes, escamas e dentes de } \\
\text { peixes, ossos de peixes, crocodilos e dinossauros. Traços } \\
\text { fósseis dispersos. }\end{array}$ & $\begin{array}{l}\text { Horizontes delgados com restos fósseis concentrados } \\
\text { provavelmente por ação de ondas e/ou correntes de maré durante } \\
\text { transgressão com retrabalhamento biogênico. }\end{array}$ \\
\hline
\end{tabular}


Tabela 2: Síntese das associações de fácies e interpretações paleoambientais para os depósitos da área de estudo.

\begin{tabular}{|c|c|c|}
\hline $\begin{array}{l}\text { ASSOCIAÇÃO DE } \\
\text { FÁCIES }\end{array}$ & DESCRIÇÃO & AMBIENTE DEPOSICIONAL \\
\hline $\begin{array}{l}\text { At/a, P/Ah, Agl, Ad } \\
\text { e Ci }\end{array}$ & $\begin{array}{l}\text { Arenito fino, bem selecionado, ocorrendo sob a forma de lobos } \\
\text { amalgamados ou separados por finas camadas de argilitos e/ou } \\
\text { conglomerados intraformacionais. O conjunto de fácies exibe } \\
\text { granocrescência e espessamento de camadas ascendentes. }\end{array}$ & FRENTE DELTAICA \\
\hline $\begin{array}{l}\text { App, Alo, As, P/Ah, } \\
\text { Ad, Agl, Cf e Ci }\end{array}$ & $\begin{array}{l}\text { Arenito fino, bem selecionado com estratificação cruzada } \\
\text { de baixo ângulo, que ocorre em camadas tabulares e, menos } \\
\text { freqüentemente, lobos. }\end{array}$ & $\begin{array}{l}\text { FRENTE DELTAICA COM } \\
\text { RETRABALHAMENTO DE ONDA }\end{array}$ \\
\hline $\begin{array}{l}\text { Agl, Ad, Alc, Alo, } \\
\text { At/a e P/Ah }\end{array}$ & $\begin{array}{l}\text { Depósitos argilosos e heterolíticos, intercalados com camadas } \\
\text { de arenito, localmente calcífero, cuja geometria varia de lobada } \\
\text { a tabular. }\end{array}$ & BARRA DISTAL \\
\hline $\begin{array}{l}\mathrm{Agl}, \mathrm{Agm}, \mathrm{Ad}, \mathrm{Alc} \\
\text { e Cs }\end{array}$ & $\begin{array}{l}\text { Domínio de argilitos laminados que gradam a maciços para cima } \\
\text { e camadas de calcários com grãos siliciclásticos. Os calcários } \\
\text { podem exibir topos com feições cársticas, gretas de contração, } \\
\text { marcas de raízes e, localmente pegadas de dinossauros, além } \\
\text { de fósseis de vertebrados e invertebrados marinhos bem } \\
\text { preservados que ocorrem de forma dispersa ou concentrados. }\end{array}$ & $\begin{array}{l}\text { PRODELTA/PLATAFORMA RESTRITA/ } \\
\text { PLANÍCIE DE LAMA }\end{array}$ \\
\hline
\end{tabular}

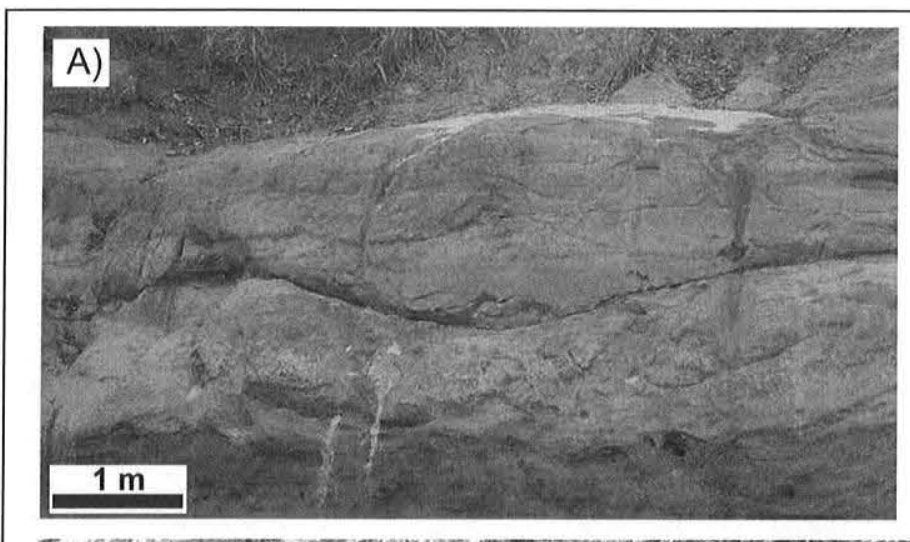

D)
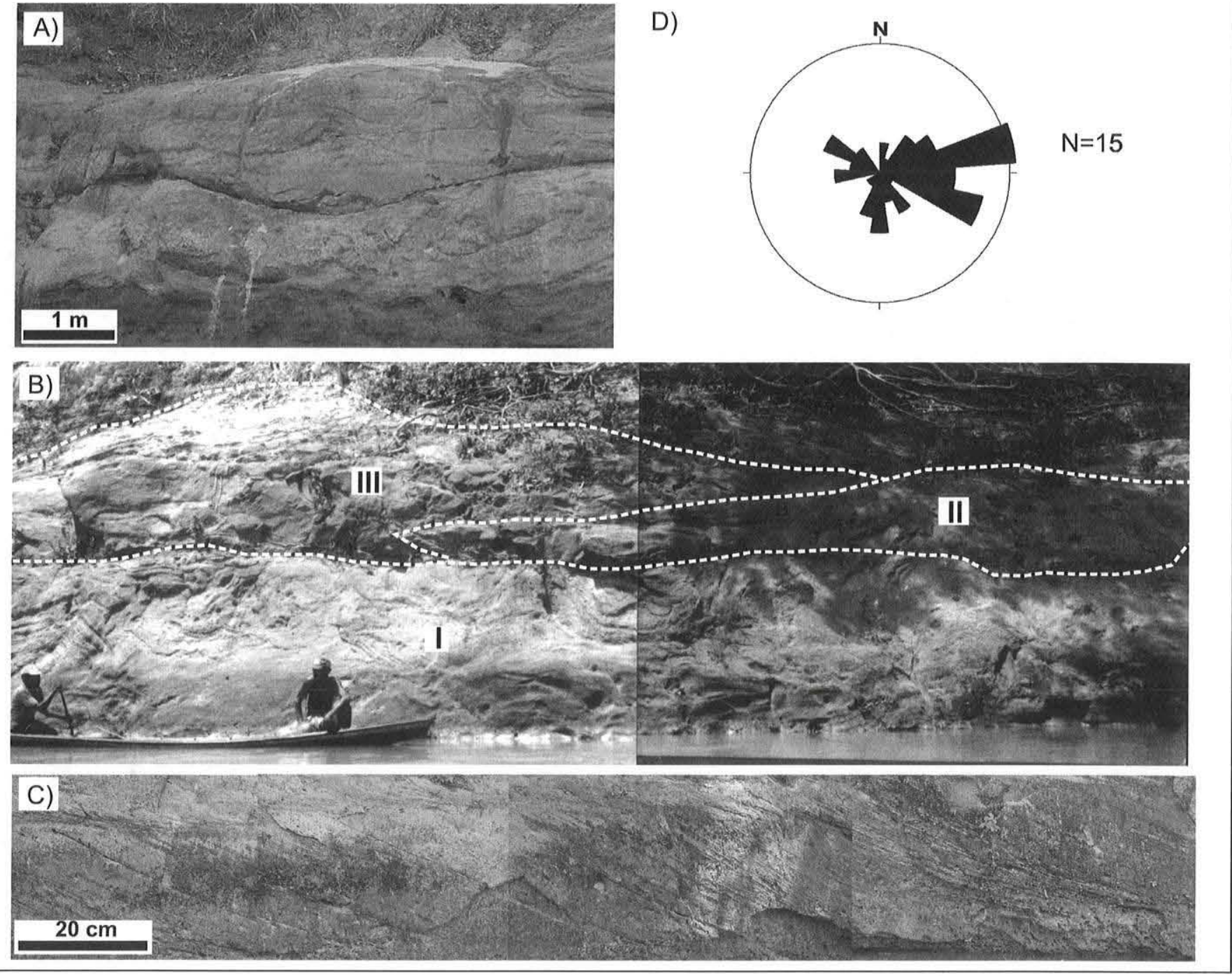

Figura 2. Associação de fácies A: frente deltaica. A) Geometria em lobos amalgamados. B) Corpo de arenito contendo sucessão de três lobos amalgamados (I a III) e internamente com intensa deformação sin-sedimentar (fácies Ad). C) Detalhe de lobo de arenito com estratificação cruzada tabular (fácies At/a). D) Paleocorrentes obtidas de estratificações cruzadas tabulares e acanaladas, mostrando domínio de paleofluxo para leste/sudeste. 

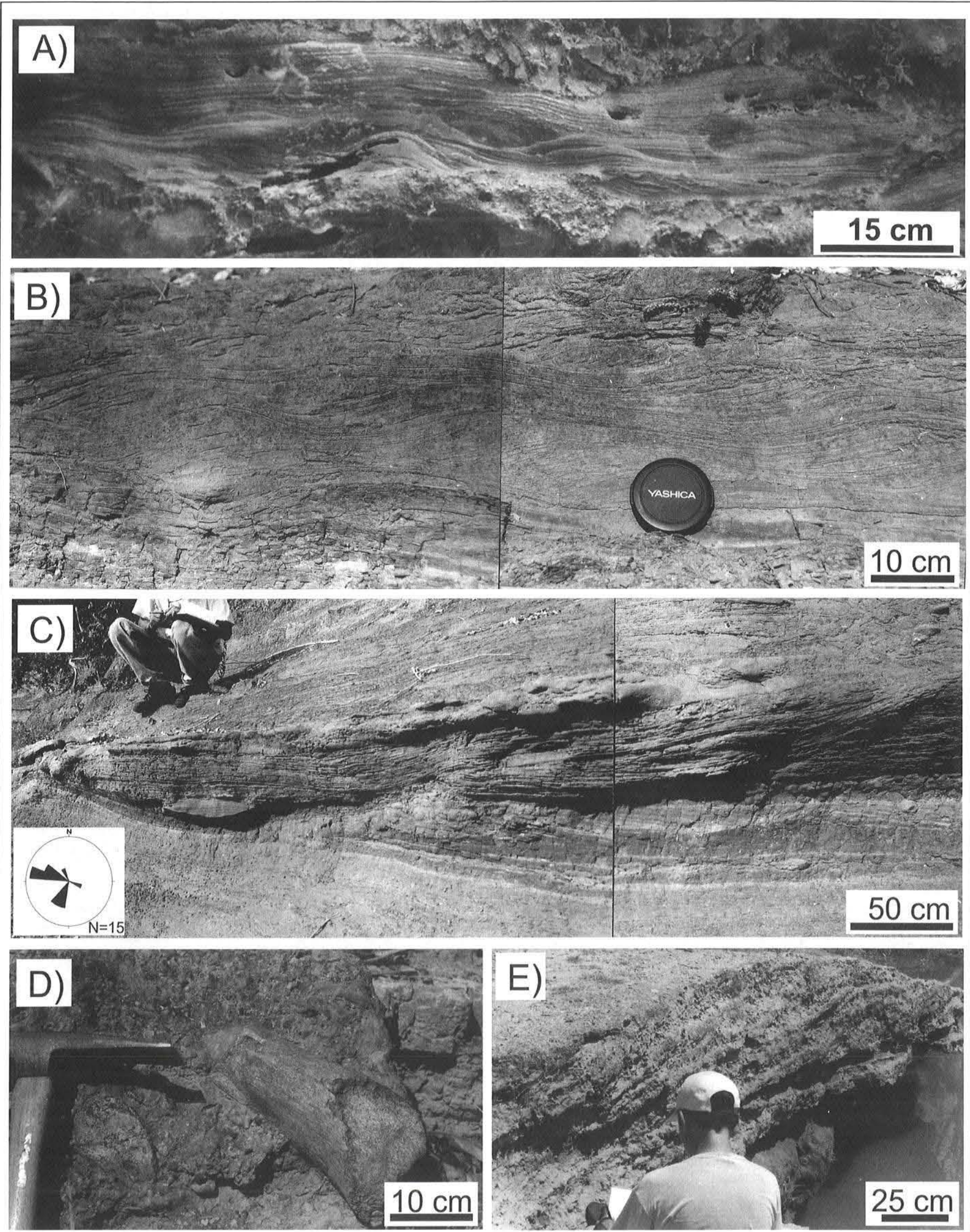

Figura 3. Associação de fácies B: frente deltaica com retrabalhamento de onda. A) Arenito com laminação cruzada cavalgante gradando para cima a plano-paralela ondulante (fácies Alo). B) Arenito com estratificação cruzada cavalgante gerada por fluxo combinado (notar limite de sets ondulantes). C) Estratificação cruzada swaley, com diagrama em roseta mostrando a direção principal do fluxo combinado. D) Conglomerado fossilifero, destacando fragmento de vertebrado (disossauro). E) Conglomerado fossilifero com estratificação cruzada. 

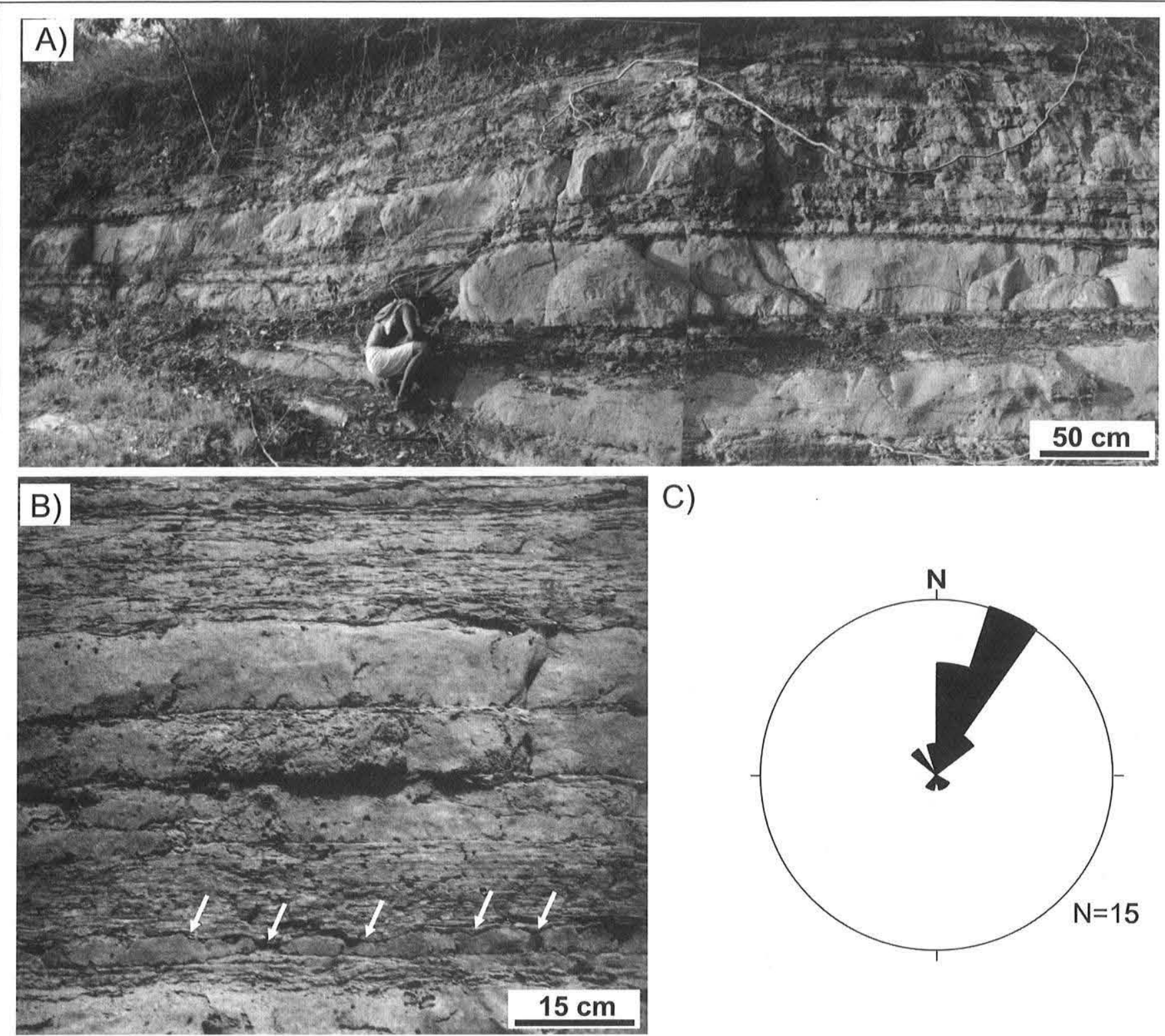

C)

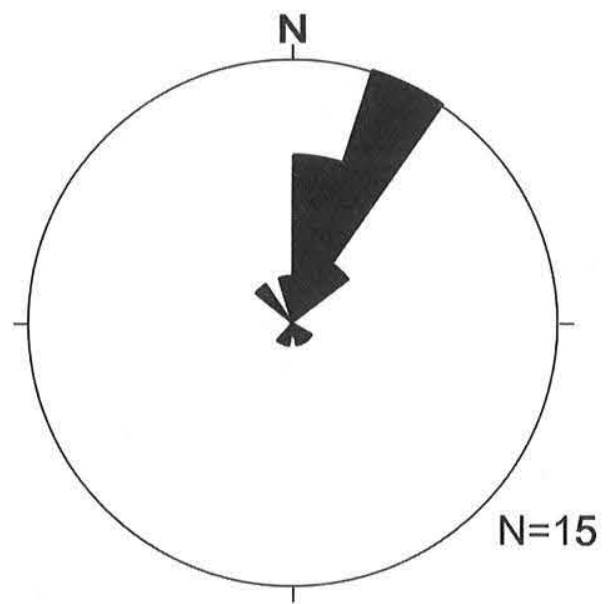

Figura 4. Associação de fácies C: barras distais: A) Vista geral das barras de arenito com geometria lenticular separadas por depósitos heteroliticos (fácies P/Ah). B) Detalhe com barras arenosas separadas por depósitos heteroliticos do tipo wavy (setas indicam superfície com marcas de onda simétrica e assimétricas). C) Paleocorrente indicada por estratificações/laminações cruzadas tabulares e acanaladas (fácies At/a).

distais e frente deltaica, interpreta-se que os argilitos e calcários sejam produtos de sedimentação em áreas distantes da influência dos lobos deltaicos, sendo possivelmente representativos de um embaiamento ou golfo. Assim, os depósitos prodeltaicos achamse intercalados a depósitos aqui definidos como plataforma restrita, onde faunas oportunísticas se proliferaram. O arranjo de fácies em ciclos, formados por gradação para cima de argilitos laminados a maciços e endurecidos, é atribuído a arrasamentos ascendentes, que culminaram com períodos de exposição subaérea e à água meteórica, cujos registros são mais evidentes nas porções marginais do sistema. Amplas planícies de lama teriam dominado nas margens da plataforma restrita, produzindo os argilitos maciços, que estiveram constantemente submetidos à ação de processos pedogenéticos. A presença de pegadas de dinossauros no topo de horizontes de calcários confirma que estas litologias se formaram nas zonas de inter- a supramaré sendo, portanto, sujeitos á exposição subaérea. A grande abundância de fácies sedimentares com gretas de contração, marcas de raízes e paleossolos, denota associação íntima com ambientes sujeitos a freqüentes exposições subaéreas, mais provavelmente representativos de planícies de lama formadas em regiões marginais da plataforma (cf. Strasser 1991; Tucker 1994; Plat \& Wright, 1992; Walker \& James 1992; Reading 1996).

Considerando-se o domínio de condições mixohalinas, uma possibilidade seria a existência de um sistema estuarino dominado por ondas. Este tipo de sistema deposicional comporta perfeitamente a presença de deltas, que podem se desenvolver tanto na cabeceira do estuário, quanto em sua porção mais distal, onde ocorrem deltas de maré em associação com o complexo de ilha barreira. Entretanto, estas possibilidades parecem remotas para o caso da área de estudo. Isto porque os depósitos representativos de lobos deltaicos aumentam em abundância em direção à porção sudeste da área, ou seja, onde ocorrem menos depósitos argilosos atribuídos aqui aos ambientes de prodelta, plataforma 

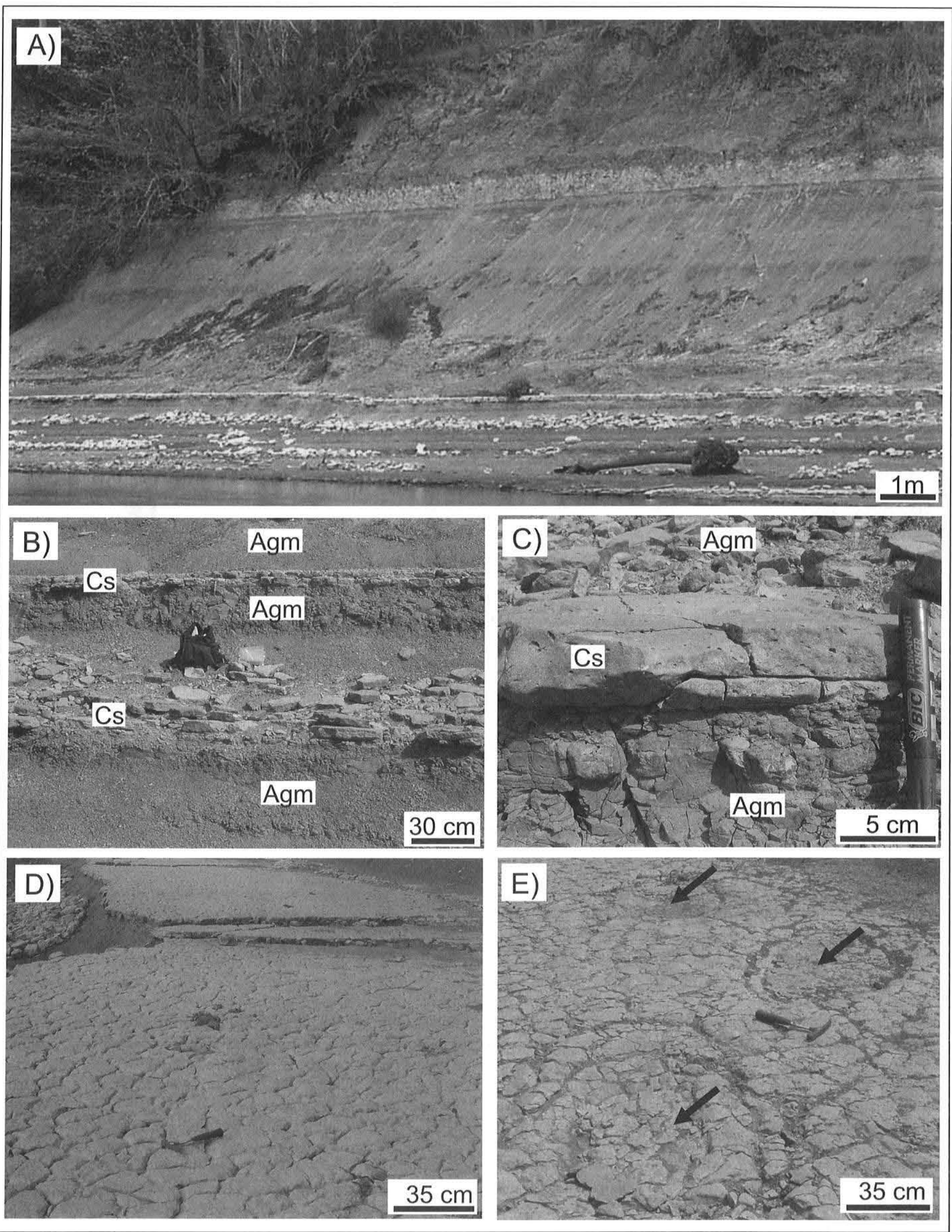

Figura 5. Associação de fácies D: prodelta/plataforma restrita/planície de lama. A) Vista geral de afloramento formado por intercalações de argilito laminado ou maciço (fácies Agl e Agm), arenito maciço calcífero (fácies Am) e calcáreos com siliciclásticos (Cs) dispostos em camadas horizontais. B, C) Detalhes de ciclos constituídos por argilitos maciços (Agm) $e$ calcários (Cs) D, E) Vista em planta de horizonte de calcário com gretas de contração (D) e ichnofósseis atribuídos a pegadas de dinossauros (E). 
Tabela 3: Síntese das microfácies carbonáticas e processos de formação correspondentes.

\begin{tabular}{|c|l|l|}
\hline MICROFÁCIES & \multicolumn{1}{|c|}{ DESCRIÇÃo } & \multicolumn{1}{|c|}{ PROCESSOS } \\
\hline Mudstone & $\begin{array}{l}\text { Matriz micrítica e com textura clotted. Aloquímicos } \\
\text { representados, em ordem de abundância, por pelóides, } \\
\text { bioclastos de ostracodes, intraclastos micríticos e grãos } \\
\text { terrígenos. }\end{array}$ & $\begin{array}{l}\text { Deposição sob baixas condições de energia em } \\
\text { baixas profundidades. }\end{array}$ \\
\hline $\begin{array}{c}\text { Wackstone/Packstone } \\
\text { peloidal ou fossilifero }\end{array}$ & $\begin{array}{l}\text { Arcabouço cuja proporção entre quantidade matriz e } \\
\text { aloquímicos varia, ora caracterizando-se seja por zonas } \\
\text { de domínio de matriz micrítica e aloquímicos (> 10\%) } \\
\text { dispersos, seja por zonas contendo pouca matriz e grãos } \\
\text { densamente empacotados. Os aloquímicos também variam } \\
\text { emabundância, com alternância entre domínio de peloides } \\
\text { e bioclastos de ostracodes. }\end{array}$ & $\begin{array}{l}\text { Deposição em ambiente raso, com circulação } \\
\text { variando de restrita a moderada, no nível ou logo } \\
\text { abaixo da linha de base da onda. }\end{array}$ \\
\hline $\begin{array}{c}\text { Packstone com } \\
\text { siliciclásticos }\end{array}$ & $\begin{array}{l}\text { Matriz micrítica, homogênea e de cor marrom escura. } \\
\text { Biomorfos e bioclastos de bivalves e gastrópodes } \\
\text { abundantes. Domínio de terrígenos, representados por } \\
\text { quartzo e feldspato, concentrados em faixas planas } \\
\text { paralelas. }\end{array}$ & $\begin{array}{l}\text { Transporte e deposição de partículas provenientes } \\
\text { de zonas de maior turbulência em zonas mais } \\
\text { calmas. Deposição em zona costeira, sujeita ao } \\
\text { influxo continental. }\end{array}$ \\
\hline $\begin{array}{c}\text { Grainstone ostracodal } \\
\text { arcabouço densamente empacotado, com grãos } \\
\text { aloquímicos constituídos por ostracodes tipicamente } \\
\text { estirados, e localmente com cimentação de calcita espática } \\
\text { fina. }\end{array}$ & $\begin{array}{l}\text { Deposição por fluxos mais energéticos em ambiente } \\
\text { de nível energético relativamente alto, comum em } \\
\text { regiões de intermaré. }\end{array}$ \\
\hline
\end{tabular}

restrita e planície de lama. Este comportamento não seria esperado no caso de deltas de maré, que se formariam na porção mais distal do sistema em associação, seja com depósitos de laguna (delta de maré enchente), seja com depósitos marinho-marginais (delta de maré vazante). Ao mesmo tempo, feições diagnósticas da ação de correntes de maré não foram registradas, o que seria comum em ambientes deste tipo. Ainda considerando-se um sistema estuarino, estes depósitos progradacionais poderiam alternativamente registrar deltas de cabeceira de baía. Apesar da localização interna no estuário, este tipo de ambiente pode sofrer efeito de correntes de maré, que se amplificam ao longo do canal estuarino. Este sistema é afetado por ondas somente em suas porções mais distais, uma vez que estas são rapidamente dissipadas pela presença de barreiras em sua desembocadura. Esta característica levou à consideração de que os depósitos deltaicos estudados não poderiam ter sido desenvolvidos na cabeceira de estuários, já que os processos de retrabalhamento dominantes são atribuídos à ação de ondas de tempo bom e de tempestade.

Levando-se em consideração o acima exposto, torna-se difícil adotar um sistema estuarino do tipo dominado por onda que possa comportar os diferentes ambientes deposicionais reconhecidos nos depósitos estudados. Portanto, é mais razoável propor a presença de um sistema deltaico propriamente dito que progradou em bacia com influência marinha, mas onde dominavam condições estressantes devido à mistura de água doce e salgada, o que favorece a existência de um "embaiamento" ou golfo. Situação semelhante é descrita por Nava-Sanchez et al. (1999) para sedimentos localizados na margem sudoeste do Golfo da Califórnia, em uma área semi-protegida, a Baía La Paz. Nessa região, são descritos sedimentos do El Coyote fan delta que, embora em contexto protegido, é um delta dominado por ondas.

Caso o modelo proposto aqui de um complexo paleoambiental contendo corpos deltaicos conectados a um golfo esteja correto, o padrão de paleocorrentes leva à reconstituição de uma paleocosta orientada grosseiramente na direção NNW-SSE, com progradação para ENE/E e ESE, como sugerido pelas estratificações cruzadas dos lobos deltaicos e canais distributários. Assim, a porção SE da área de estudo representaria o posicionamento mais proximal do sistema, onde dominavam influxos arenosos, enquanto que a porção NW se constituía nos ambientes mais distais, dominados gradativamente por deposição por suspensão com episódicas introduções de fluxos arenosos, formando barras distais. O distanciamento do influxo de areia e o maior intercâmbio com águas marinhas teriam favorecido a formação de horizontes calcários a NW do sistema deposicional. O aumento na freqüência de depósitos representativos de ação por ondas de tempestade naquela direção também reforça esta interpretação. O ambiente de baixa energia com morfologia de golfo teria sofrido introdução de areia oriunda de leste/nordeste a partir de ambientes marinhos via fluxos combinados (cf. Bhattacharya \& Walker 1992; Reinson 1992).

A interpretação paleoambiental ora apresentada também é reforçada por meio de comparação entre as características sedimentológicas destes depósitos com outros localizados na Bacia de Grajaú, como por exemplo, aqueles atribuídos à Formação Alcântara, de idade albiana/cenomaniana, exposta no norte desta bacia. Esta unidade também inclui arenitos, argilitos e calcários representativos de sistema deposicional estressado, onde o efeito de ondas de tempestade produziu estruturas sedimentares similares às descritas neste trabalho. Além disto, outros depósitos cretáceos expostos na borda sudoeste da Bacia do Grajaú são também atribuídos a sistemas deposicionais similares, como por exemplo, aqueles expostos nas áreas de Açailândia (Anaisse Jr 1999; Rossetti et al. 2000) e Grajaú (Rossetti \& Góes 2003). Dada a ausência de dados bioestratigráficos em todas estas localidades, torna-se difícil demonstrar que todos estes estratos cretáceos sejam estratigraficamente correlacionados. Porém, se este for o caso, então a proposição de um amplo golfo raso, como sugerido em Anaisse Jr. (1999), seria o mais provável. Este poderia eventualmente apresentar sistemas deposicionais mais restritos devido à presença de barreiras, o que parece ter 
Fase 1: Progradação da linha de costa, com deposição de volume significativa de areia sob forma de lobos de suspensão.

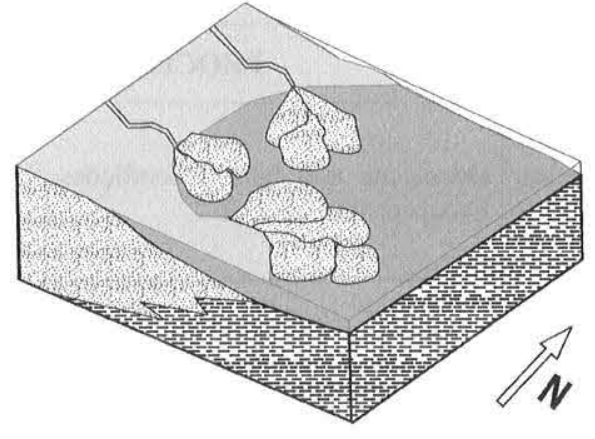

Fase 2: Recuo da linha de costa devido à transgressão e conseqüente inibição da formação de lobos de suspensão.

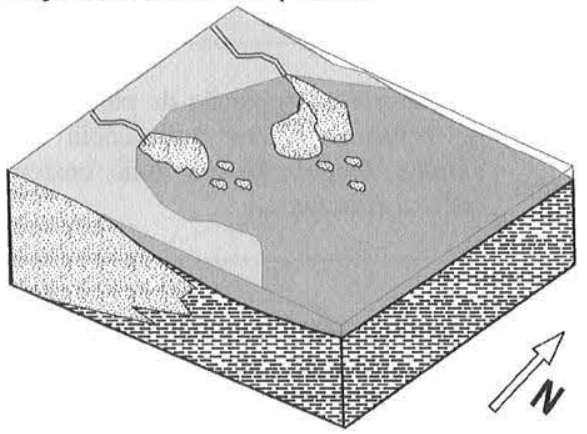

Fase 3: Com a diminuição de influxo terrígeno na bacia devido à continuidadedo processo transgressivo, o sistema deposicional torna-se favorável à formação de carbonatos, que se acumulam em ambientes rasos, caracterizados pelos depósitos de plataforma restrita.

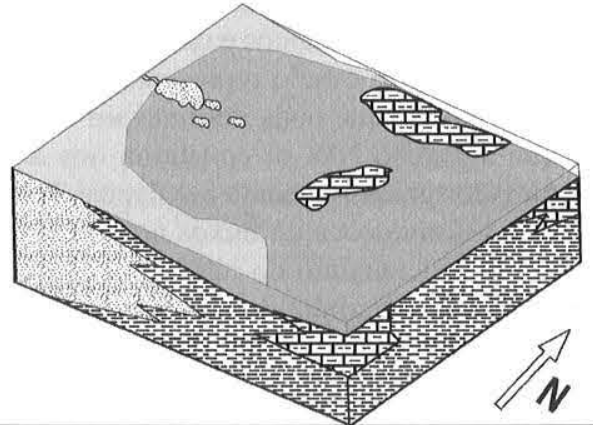

Figura 6. Modelo esquemático ilustrando o paleoambiente de deposição na área de estudo durante o Eo/Mesocretáceo, representado por uma larga reentrância na costa do tipo golfo com forte influência de ondas normais e de tempestade, que evoluiu de uma fase progradacional para transgressiva.

sido o caso para a área de Alcântara.

ARQUITETURA DEPOSICIONAL As associações faciológicas aqui descritas ocorrem organizadas sob forma de três sucessões estratigráficas limitadas por superfícies de descontinuidade (Fig. 7A).

Sucessão inferior Esta sucessão, com espessura máxima de $8 \mathrm{~m}$, é constituída por ciclos de arrasamento ascendente de até 2 $m$ de espessuras médias. Estes são, em geral, indicados pela gradação, da base para o topo, de depósitos formados em posições progressivamente mais proximais do sistema deltaico, revelado pela superposição de associações faciológicas atribuídas a ambientes de baixa energia relacionado com um golfo, barra distal e frente deltaica. Além disto, esta unidade estratigráfica mostra domínio de depósitos de frente deltaica na porção sudeste da área de estudo, com gradação para depósitos progressivamente mais distais, isto é prodelta, plataforma restrita, planície de lama, frente deltaica influenciada por onda e barras distais em direção à sua porção noroeste. A base da sucessão não é visível, porém seu topo é definido por uma superfície aqui codificada como S1 e caracterizada por relevo erosivo de até $5 \mathrm{~m}$, que a separa da sucessão intermediária sobrejacente. Esta superfície ascende em direção a noroeste da área de estudo, sendo acompanhada pelo progressivo aumento na preservação de ciclos de arrasamento ascendente contendo fácies com evidências de exposição subaérea, revelada por perfis de solo mais freqüentes e espessos.

Sucessão intermediária Esta sucessão possui espessura máxima de $7 \mathrm{~m}$ na porção sudeste da área de estudo, porém adelgaça para noroeste, onde atinge apenas cerca de $3 \mathrm{~m}$ de espessura. Inclui depósitos atribuídos a ambientes de frente deltaica, barra distal e prodelta, plataforma restrita e planície de lama. A base desta unidade é dominada por depósitos argilosos e/ou carbonáticos, os primeiros com excelente preservação da coloração cinza escuro original, de onde se recuperaram os fósseis de invertebrados e de material palinológico. Também no extremo noroeste desta unidade registrou-se lente de folhelhos negros contendo um volume excepcionalmente rico de fósseis de invertebrados com carapaças extremamente bem preservadas, misturadas a abundantes restos vegetais. Acima deste intervalo basal, onde os ciclos de arrasamento ascendente chegam a atingir até $3 \mathrm{~m}$ de espessura, ocorrem ciclos mais delgados, que culminam com horizontes intempéricos, eventualmente com marcas de raízes. Nesta sucessão a zona de intergradação com os depósitos de prodelta, plataforma restrita e planície de lama, é deslocada para SE em relação ao posicionamento desta interface na sucessão inferior, o que resultou na freqüente superposição de depósitos de prodelta, plataforma restrita e planície de lama sobre depósitos de barras distais e frente deltaica.

O topo da sucessão intermediária é uma superfície abrupta, adotada como datum, dada sua continuidade lateral e seu fácil reconhecimento na área de estudo, devido a presença de estratos arenosos grossos a conglomeráticos e conglomerados, que formam camada de até $1 \mathrm{~m}$ de espessura, mas que localmente se constituem em lags de apenas 2 a $5 \mathrm{~cm}$ de espessura. Além disto, este horizonte com material detrítico distintamente mais grosso que todo o resto das litologias documentadas na área de estudo, contém abundantes restos fósseis de vertebrados e invertebrados.

Sucessão superior Apresenta espessuras que variam de poucos centímetros a cerca de $12 \mathrm{~m}$, sendo formada pelo domínio de depósitos atribuídos a prodelta, plataforma restrita e planície de lama, cujo aumento em volume se dá de sudeste para noroeste da área de estudo. Da mesma forma como ocorre na passagem entre as duas unidades inferiores, as fácies de prodelta, plataforma restrita e planície de lama são mais amplamente distribuídas, atingindo áreas localizadas relativamente mais a sudeste, o que resulta novamente em sua freqüente sobreposição a depósitos de frente deltaica e barras de desembocadura da sucessão subjacente. Além dos depósitos de prodelta, plataforma restrita e planície de lama, a sucessão superior apresenta também depósitos de barras distais, com os quais formam os ciclos com características de arrasamento ascendente. Registra-se diminuição na freqüência de depósitos de barras distais de sudeste para noroeste ao longo desta sucessão, com adelgaçamento e, comumente, desaparecimento destes naquela direção.

Evolução do sistema deposicional A análise arquitetural das unidades estratigráficas acima descritas permite propor que o sistema deposicional deltaico sofreu progressivo afogamento, através do tempo. Isto é demonstrado pelo padrão estratal retrogra- 


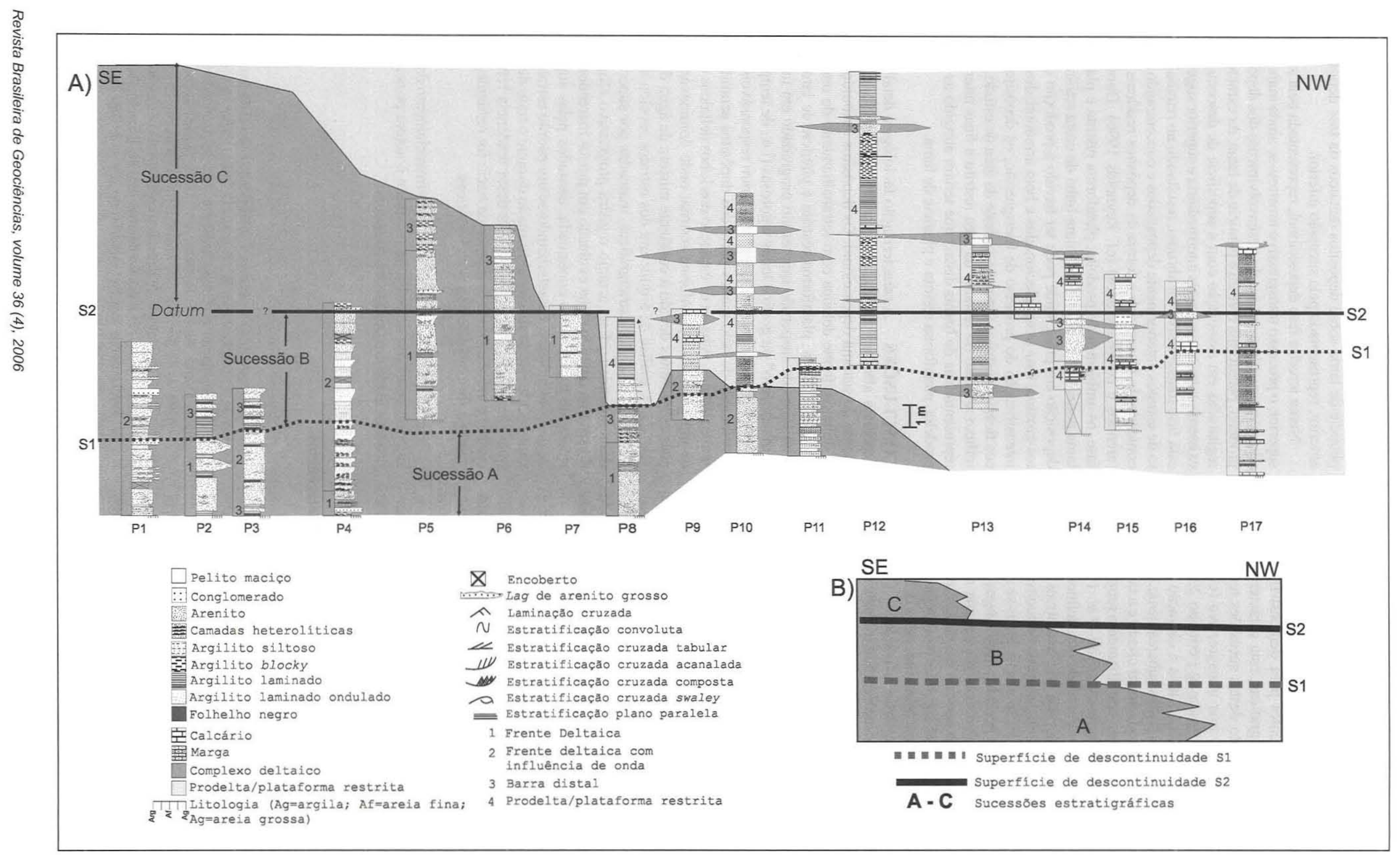

Figura 7. A) Correlação estratigráfica dos perfis estratigráficos proposta para a área de estudo. O datum escolhido baseia-se em superficie de descontinuidade correlacionável na maioria das sessões estudadas (ver localização dos perfis Pl a P17 na figura 1). B) Representação esquemática do padrão estratal representado pelas sucessões deposicionais 
dacional, caracterizado por unidades estratigráficas apresentando associações de fácies de prodelta, plataforma restrita e planície de lama que se posicionam progressivamente ascendente em direção ao continente, sobrepondo-se a fácies deltaicas desenvolvidas em fases prévias (Fig. 7A, B). Embora as informações disponíveis não sejam suficientes para demonstrar a natureza regional das sucessões estratigráficas, esta característica leva a sugerir que o desenvolvimento destas sucessões tenha se dado durante o trato de sistema de mar transgressivo (cf. Vail et al. 1991, Myers \& Milton 1996, Assine \& Perinotto 2001). Rápida elevação do nível do mar relativo leva à elevação do nível de base e à inundação de áreas expostas subareamente. A combinação entre o novo espaço acomodacional criado e a taxa de elevação do nível do mar relativo gera empilhamento retrogradacional e deposição em contexto transgressivo (Vail et al. 1991). Sendo assim, as superfícies de descontinuidade que definem os limites das sucessões estratigráficas, seriam representativas de períodos de inundação (cf. Reynolds 1996, Assine \& Perinotto 2001). Embora estas superfícies de inundação assemelhem-se a superfícies transgressivas, estas requerem períodos mais longos e condições marinhas mais profundas. A evolução do sistema deposicional representado na área de estudo ocorreu em pulsos marcados por períodos de afogamentos mais significativos, registrados pelas superfícies de descontinuidade e pelas sucessões definidas a partir da análise arquitetural dos estratos estudados.

Assim sendo, a sucessão estratigráfica inferior registra fase de maior desenvolvimento da progradação deltaica, quando um volume significativo de areias foi depositado, atingindo grande parte da área de estudo. Durante esta fase, os depósitos de prodelta, plataforma restrita e planície de lama estiveram restritos à extremidade noroeste da área de estudo, onde períodos com deposição de argilas alternavam-se com períodos favoráveis à precipitação de carbonatos. A formação destes provavelmente teria ocorrido durante momentos de inibição de influxo arenoso, como documentado em ambientes deposicionais similares (p.e., Kendall \& Schlager 1981; Strasser 1991). Apesar da natureza dominantemente progradacional dos estratos durante esta fase de desenvolvimento do sistema deposicional, a progressiva elevação do nível do mar relativo que já se fazia presente pode ter gerado sucessivos episódios de inibição na progradação dos lobos arenosos, favorecendo a formação de carbonatos.

A sucessão intermediária registra um momento em que a tendência transgressiva do sistema deposicional mostrava-se mais pronunciada, com o maior recuo da linha de costa relativamente à fase anterior. Com isto, o local de desenvolvimento principal de barras de desembocadura foi deslocado para uma posição mais proximal, fazendo com que os ambientes de baixa energia relacionados ao golfo avançassem em direção ao continente, ou seja, para sudoeste da área de estudo (considerando-se paleocosta orientada na direção norte-sul, como proposto pelo padrão de paleocorrentes). Com isto, houve a possibilidade de superposição de depósitos de prodelta, plataforma restrita e planície de lama sobre depósitos deltaicos da fase deposicional anterior, representada pela sucessão inferior.

Numa terceira fase deposicional, representada pela sucessão superior, o processo transgressivo mostrou-se ainda mais acentuado, o que resultou em amplo desenvolvimento dos depósitos de prodelta, plataforma restrita e planície de lama. As características registradas em associação com a superfície de descontinuidade existente entre as sucessões intermediária e superior sugerem que esta fase transgressiva foi abrupta, resultando no retrabalhamento de estratos anteriormente depositados e concentrando elevado conteúdo de fósseis sob a forma de depósitos residuais grossos (arenitos e conglomerados) (cf. Reynolds 1996). Durante esta fase, os ambientes de prodelta, plataforma restrita e planície de lama podem ter evoluído para uma linha de costa retilínea, com deposição em praia, onde pode ter havido a produção de arenitos grossos, mas bem selecionados e bem arredondados. Com a intensificação do processo de transgressão, os depósitos deltaicos ficaram restritos à porção sudeste da área de estudo, sendo o influxo arenoso no restante da área restrito a finas intercalações representativas de barras distais que teriam atingido as áreas de prodelta, plataforma restrita e planície de lama.

CONCLUSÕES A caracterização faciológica detalhada dos depósitos albianos estudados permitiram um melhor entendimento do sistema deposicional. Os depósitos atribuídos à frente deltaica, frente deltaica com retrabalhamento de onda, barra distal e prodelta, plataforma restrita e planície de lama, registram lobos de suspensão que teriam progradado em um amplo "embaimento" ou golfo. Ondas vigorosas (i.e., de tempestades) e, possivelmente correntes de maré, foram responsáveis pela redistribuição de pelo menos parte dos depósitos acumulados na frente deltaica. A bacia de captação dos lobos deltaicos consistia de um golfo com plataforma restrita, onde dominavam condições estressantes devido à constante mistura de água doce com salgada. A análise da arquitetura dos estratos revelou a presença de três unidades estratigráficas, marcadas por superfícies de descontinuidade. Este arranjo registra progressivo afogamento do sistema deltaico e sua evolução em pulsos marcados por períodos de transgressão continuada, atestados pelas superfícies de descontinuidade, caracterizando-se um padrão estratal dominantemente retrogradacional formado durante o trato de sistema transgressivo. Como conseqüência desta tendência retrogradacional, a introdução de terrígenos na bacia foi reduzida, promovendo a formação de fácies carbonáticas.

Agradecimentos Ao CNPq, pelo financiamento da pesquisa e fornecimento de bolsa de mestrado à autora principal e de produtividade em pesquisa à co-autora.

\section{Referências}

Adams A.E. \& Mackenzie W.S. 1998. A colour atlas of carbonate sediments and rocks under the microscope. Manson Publishing, $180 \mathrm{p}$.

Allen J.R.L. 1980. Sand waves: a model of origin and internal structure. Sedimentolary Geology, 26:281-328.

Allen J.R.L. 1982. Sedimentary Structures: Their character and physical basis. Amsterdam, $663 \mathrm{p}$.

Amos C.L., Li M.Z., Choung K.S., 1996. Storm-generated, hummocky stratification on the outer-scotian shelf. Geo-Marine Letter, 16: 8594.

Anaisse Júnior J.1999. Fácies costeiras dos depósitos Itapecuru (Cretáceo), Região de Açailândia, Bacia do Grajaú. Dissertação de Mes- trado, Centro de Geociências, Universidade Federal do Pará, 86 p. Anaisse Jr. J., Truckenbrodt W., Rossetti D. 2001. Fácies de um sistema estuarino-lagunar no Grupo Itapecuru, área de Açailândia/MA, Bacia do Grajaú. In: D.F. Rossetti, A.M. Góes, W. Truckenbrodt (eds.) O cretáceo na Bacia de São Luís-Grajaú, Belém, pp.:119-150.

Arai M. 2001. Palinologia de depósitos cretáceos no norte e meio-norte do Brasil: histórico e estado-de-arte. In: D.F Rossetti, A.M. Góes, W. Truckenbrodt (eds.) O cretáceo na Bacia de São Luís-Grajaú, Belém, pp.:175-190.

Arnott R.W. \& Southard J.B. 1990. Exploratory flow-duct experiments on combined-flow bed configurations, and some implications for 
interpreting storm-event stratification. Journal of Sedimentary Petrology, 60:211-219.

Assine M.L. \& Perinotto J.A.J. 2001. Estratigrafia de seqüências em sistemas deposicionais siliciclásticos costeiros e marinhos. In: H.J.P. Severiano Ribeiro (org.) Estratigrafia de Seqüências: fundamentos e aplicações. São Leopoldo, pp.:305-340.

Azevedo R.P. 1991. Tectonic Evolution of Braziilian Equatorial Continental Margin Basins. Tese de Doutoramento, London, Royal School of Mines Imperial College, 412p.

Bhattacharya J.P. \& Walker R.G. 1992. Deltas. In: R.G. Walker \& N.P. James (eds.) Facies Models-Response to sea level change. Toronto, Geological Association of Canada, pp.: 157-178.

Cheel R.J. \& Leckie D.A. 1993. Hummocky cross-strati.cation. In: V.P. Wright (ed.) Sedimentology Review/1. Cambridge, Blackwell Scientific Publication. pp.: 103-122.

Coleman J.M. 1988. Dynamic changes and processes in the Mississippi River delta. American Association of Petroleum Geologists Bulletin., 100:999-1015.

Colquhoun G.P. 1995. Siliciclastic sedimentation on a storm- and tideinfluenced shelf and shoreline: the Early Devonian Roxburgh Formation, NE Lachlan Fold Belt, southeastern Australia. Sedimentary Geology, 97:69-98.

Dalrymple R.W. 1992. Tidal depositional systems. In: R.G.Walker (ed.) Facies Models: Response to Sea Level Change. Geological Association of Canadá, pp.: 195-218.

Duke W.L., Arnott R.W.C., Cheel R.J. 1991. Shelf sandstone and hummocky cross stratification: new insights on a storm debate. Geology, 19:625-628.

Elliot T. 1986. Deltas. In: H.G. Reading (ed.) Sedimentary environments and facies. Oxford, Blackwell, pp.:113-154.

Glover B. W. \& O'Beirne A.M. 1994. Anatomy, hydrodynamic and deposition setting of a Westiphalian C lacustrine delta complex, West Midlands, England. Sedimentology, 41:115-132.

Góes A.M. \& Rossetti D.F. 2001. Gênese da Bacia de São Luís-Grajaú, Meio-Norte do Brasil. In: D.F. Rossetti,A.M. Góes, W. Truckenbrodt (eds.) O cretáceo na Bacia de São Luís-Grajaú, Belém, pp.:15-30.

Harris C.W., Eriksson K.A. 1990. Allogenic controls on the evolution of storm to tidal shelf sequences in the early Proterozoic Un-compahgre Group, southwest Colorado, USA. Sedimentology, 37:189-213.

Hill P.R., Meulé S., Longuépée H. 2003. Combined-flow processes and sedimentary structures on the shoreface of the wave-dominated Grande-Rivière-De-La-Baleine Delta. Journal of Sedimentary Research, 73(2):217-226.

Johnson H.D. \& Baldwin C.T. 1986. Shallow siliciclastic seas. In: H.G. Reading (Ed.) Sedimentary Environments and Facies. Oxford, Blackwell Scientific Publication, pp. 229-282.

Kendall C.St.C.G \& Schlager W. 1981. Carbonates and relative changes in sea level. Marine Geology, 44:181-212.

Leckie D.A. \& Walker R.G. 1982. Storm-and-tide-dominated shorelines in cretaceous moosebar-lower gates interval outcrops equivalents of deep basin gas trap in western Canadá. American Association of Petroleum Geologists Bulletin, 66(2):138-157.

Mills P.C. 1983. Genesis and diagnostic value of soft-sediment deformation structures: a review. Sedimentary Geology, 35:83-104.

Myers K.J. \& Milton N.J. 1996. Concepts and principles of sequence stratigraphy. In: D. Emery \& K.J. Myers (eds.) Sequence Stratigraphy. Blackwell Science, pp.: 11-44.

Nava-Sanchez E.H., Gorsline D.S., Cruz-Orozco R., Godinez-Orta L. 1999. The El Coyote fan delta: A wave-dominated example from the Gulf of Califórnia, Mexico. Quaternary International, 56:129-140.

Orton G.J. \& Reading H.G. 1993. Variability of deltaic processes in terms of sediment supply, with particular emphasis on grain size. Sedimentology, 40:475-512.

Paz J.D.S. 2000. Análise Faciológica da Formação Codó (Aptiano Superior) na região de Codó (MA), leste da bacia do Grajaú. Dissertação de Mestrado, Centro de Geociências, Universidade Federal do Pará, $117 \mathrm{p}$.

Paz J.D.S. \& Rossetti D.F. 2001. Reconstrução paleoambiental da Formação Codó (Aptiano), borda leste da Bacia do Grajaú, MA. In: D.F. Rossetti, A.M. Góes, W. Truckenbrodt (eds.) O cretáceo na Bacia de
São Luis-Grajaú, Belém. p.77-100.

Platt N.H. \& Wright V.P. 1992. Palustrine carbonates and the Florida Everglades: towards an exposure index for the fresh-water environment? Journal of Sedimentary Petrology, 62:1058-1071.

Reading H.G. (ed.) 1996. Sedimentary environments: processes, facies and stratigraphy. Balckwell, Oxford, 688p.

Reinson G.E. 1992. Transgressive barrier island and estuarine systems. In: R.G. Walker \& N.P. James (eds.) Facies Models- Response to sea level change. Toronto, Geological Association of Canada, p.179194.

Reynolds T. 1996. Paralic Sucessions. In: D. Emery \& K.J. Myers (eds.) Sequence Stratigraphy. Blackwell Science, p. 134-177.

Rossetti D. F. 1997. Facies analysis of the lower succession of the Upper Itapecuru Formation, São Luís Basin, northern Brazil. In: M.L. Costa \& R. Angélica (eds.) Contribuições à Geologia da Amazônia. Belém, Falangola, pp.: 241-284.

Rossetti D.F. 1998. Facies architecture and sequential evolution of incised valley estuarine fills: the Upper Itapecuru Formation (São Luís Basin), northern Brazil. Journal of Sedimentary Research, 68:299310.

Rossetti D.F. 2001. Arquitetura deposicional da Bacia de São Luís-Grajaú. In: D.F. Rossetti, A.M. Góes, Truckenbrodt W. (eds.) Ocretáceo na Bacia de São Luis-Grajaú, Belém, p.31-46.

Rossetti D.F. \& Góes A.M. 2003. Caracterização paleoambiental de depósitos Albianos da borda sul da Bacia de São Luís-Grajaú: modelo de delta fluvial influenciado por tempestade. Revista Brasileira de Geociências, 33(3):299-312.

Rossetti D.F. \& Truckenbrodt W. 1997. Revisão estratigráfica para os depósitos do Albiano-Terciário Inferior(?) na Bacia de São Luis, Maranhão. Belém, MCT/MPEG, Boletim 9, p. 29-41.

Rossetti D.F., Góes A.M., Arai M. 2001a. A passagem Aptiano-Albiano na Bacia do Grajaú, MA. In: D.F. Rossetti, A.M. Góes, W. Truckenbrodt (eds.) O cretáceo na Bacia de São Luís-Grajaú. Belém, p.101117.

Rossetti D.F., Góes A.M., Paz J.D.S. 2004. Facies analysis of the Codó Formation (Late Aptian) in the Grajaú area, southern São Luís-Grajaú Basin. Anais da Academia Brasileira de Ciências, 76(4):791806.

Rossetti D.F., Truckenbrodt W., Santos Júnior A.E. 2001b. Clima do Cretáceo no Meio-Norte brasileiro. In: D.F. Rossetti, A.M. Góes, W. Truckenbrodt (eds.) O cretáceo na Bacia de São Luis-Grajaú, Belém, p. 67-76.

Rossetti D.F., Góes A.M., Truckenbrodt W., Anaisse Jr. J. 2000. Tsunami-induced large-scale scour-and-fill structures in Albian to Cenomanian deposits of Grajaú Basin, Northern Brazil. Sedimentology, 47:309-323.

Strasser A. 1991. Lagoonal-Peritidal sequences in carbonate environments: autocyclic and allocyclic processes. In: G. Einsele, W. Ricken, A. Seilacher (eds.) Cycles and Events in Stratigraphy. Berlin, Springer-Verlag, p.709-721.

Swift D.J.P., Figueiredo Jr. A.G., Freeland G.L., Oertel G.F. 1983. Hummocky cross-stratification and megaripples: a geological double standard? Journal of Sedimentary Petrology, 53:1295-1317.

Tamura T. \& Masuda F. 2003. Shallow-marine fan delta slope deposits with large-scale cross-stratification: the Plio-Pleistocene Zaimokuzawa formation in the Ishikari Hills, northern Japan. Sedimentary Geology, 158:195-207.

Tucker M.E. 1994. Sedimentary Petrology: An Introduction to the Origin of Sedimentary Rocks. Blackwell, Cambridge, 260p.

Vail P.R., Audemard F., Bowman S.A., Eisner P.N., Perez-Cruz C. 1991. The stratigraphic sgnatures of tectonics, eustasy and sedimentology - an overview. In: G. Einsele, W. Ricken, A. Seilacher (eds.) Cycles and Events in Stratigraphy. Berlin, Springer-Verlag, pp:.617-659.

Walker R.G. \& James N.P. (eds.) 1992. Facies Models-Response to sea level change. Geological Association of Canada, Toronto, 454p.

Manuscrito A1644 Aprovado em 25 de outubro de 2006 